ORIGINAL ARTICLE

\title{
Aberrant tetranectin expression in human breast carcinomas as a predictor of survival
}

\author{
P Obrist, G Spizzo, C Ensinger, D Fong, T Brunhuber, G Schäfer, M Varga, R Margreiter, \\ A Amberger, G Gastl, M Christiansen
}

See end of article for authors' affiliations

.....................

Correspondence to:

Dr P Obrist, Department of Pathology, University of Innsbruck, Muellerstr. 44, A-6020 Innsbruck,

Austria;

Peter.Óbrist@uibk.ac.at

Accepted for publication 5 September 2003

\begin{abstract}
Aims: Tetranectin (TN), a plasminogen kringle 4 binding protein, is thought to play a prominent role in the regulation of proteolytic processes via binding to plasminogen. The aim of this study was to evaluate the expression of TN in human breast cancer and adjacent normal breast tissue and to determine the impact of this expression on survival.

Methods: A retrospective analysis was performed on 189 patients with breast cancer, with a median follow up time of 10.6 years. The expression of $\mathrm{TN}$ was assessed in tumour tissue and adjacent normal breast tissue by immunohistochemistry, and the prognostic relevance of its expression in tumour cells was evaluated.

Results: TN was highly expressed in connective tissue fibres surrounding normal breast epithelium, but not in normal epithelial cells. High expression of TN in tumour cells was found in $131(69 \%)$ of the tumour samples. By western blot analysis, no significant difference in the amount and molecular weight of TN was seen between tumour tissue and normal tissue. Strong TN immunoreactivity in tumour tissue was predictive of poor disease free and tumour specific overall survival. By multivariate analysis, high TN expression in cancer cells was an independent prognostic factor for disease free and tumour specific overall survival. Conclusions: Our results demonstrate differential TN expression in normal and malignant breast tissue and a prognostic impact of TN protein expression in breast carcinoma tissue. These data suggest a possible role of TN in invasiveness and the metastatic spread of human breast cancer.
\end{abstract}

$\mathrm{T}$ tranectin (TN) is a member of the C-type lectin family and can be detected in serum and the extracellular matrix. TN is composed of three identical, noncovalently linked $20 \mathrm{kDa}$ subunits, and binds to the fourth kringle domain of plasminogen, which stimulates plasminogen activation in vitro. The human TN gene has been localised to $3 \mathrm{p}-\mathrm{p} 21.3$ and consists of three exons. ${ }^{1}$ Each separate exon encodes specific functional domains. The short exon 1 encodes the heparin binding site of TN. The second exon encodes an $\alpha$ helix protein, which governs the trimerisation of TN monomers by assembling them into a triple helical coiled structural element. The final exon encodes a C-type lectin-like domain, homologous to the carbohydrate recognition domains of calcium dependent animal lectins. ${ }^{2}$ In addition, $O$ linked glycosylation of the TN molecule at threonine 4 has been described. ${ }^{34}$

The TN protein interacts with complex sulfated polysaccharides, ${ }^{56}$ in a lysine sensitive way, specifically with apolipoprotein $\mathrm{a}^{7}$ and in a calcium dependent fashion with fibrin. ${ }^{8} \mathrm{TN}$ is produced by many different cell types, including monocytes, ${ }^{9}$ neutrophils, ${ }^{10}$ and fibroblasts. ${ }^{11}$ Furthermore, TN is a crucial component of the extracellular matrix during muscle cell development and regeneration. ${ }^{12}$ This protein is also expressed during bone development and has been proposed to have a role in mineralisation during osteogenesis. ${ }^{13}$ The distinct binding properties of TN to plasminogen and its expression in normal tissue development point to an important physiological function of $\mathrm{TN}$ in tissue formation and repair. Indeed, the concentration of $\mathrm{TN}$ in serum decreases greatly after myocardial infarction, ${ }^{14}$ suggesting consumption of circulating soluble $\mathrm{TN}$ during myocardial repair.

\begin{abstract}
"Several investigators have reported that plasma and serum tetranectin concentrations in patients with malignant tumours correlate with disease stage and survival"
\end{abstract}

TN has also been detected in malignant tissues, particularly tumours of the breast, colon, stomach, and ovary, whereas no $\mathrm{TN}$ immunoreactivity was seen in the corresponding normal epithelium of the breast, colon, or ovary. ${ }^{15-17}$ Notably, TN was colocalised together with plasminogen at the invasion front of cutaneous melanomas. ${ }^{18}$ Several investigators have reported that plasma and serum $\mathrm{TN}$ concentrations in patients with malignant tumours correlate with disease stage and survival. ${ }^{19-26}$ Others found that TN expression in tumour tissue correlated with tumour histological grading. ${ }^{27}$ The aim of our study was to evaluate the expression of TN in breast cancer tissue and in adjacent normal breast tissue and to investigate its role as a prognostic marker.

\section{MATERIAL AND METHODS}

Tissue samples and patient characteristics

Formalin fixed, paraffin wax embedded samples from 189 patients with breast cancer were obtained from the Department of Pathology, University of Innsbruck, Austria. Only tissue specimens from patients without evidence of distant metastasis, without locally advanced disease, and with axillary lymph node dissection at the time of diagnosis were included in our study. The median age of the patient population at diagnosis was 54.6 years (range, 29-85). Eighty three patients were younger than 50 years and were

Abbreviations: TBS, Tris buffered saline; TBS-T, Tris buffered saline plus Tween; TN, tetranectin 
considered premenopausal. One hundred and six patients were postmenopausal. One hundred and one patients (53\%) were node positive and $88(47 \%)$ node negative. Hormone receptor status was evaluated biochemically by the dextran charcoal method. Seventy five $(46 \%)$ of 162 patients with documented treatment schedules received adjuvant treatment (chemotherapy and/or antihormonal treatment). After diagnosis and primary surgery, the clinical status was documented by re-evaluating each patient at least once a year at the department of surgery, University of Innsbruck. The follow up procedure included physical examination, mammography, abdominal ultrasound, and chest radiography. The median follow up time was 10.6 years (range, 3-20). Tumour recurrence was defined as the advent of local relapse or distant metastases.

\section{Immunohistochemistry}

For immunohistochemistry, a monoclonal antibody (Statens Serum Institute, Copenhagen, Denmark) against TN was used. This antibody was characterised and has been tested for immunohistochemistry with proper controls. ${ }^{28}$ Tissue sections ( $5 \mu \mathrm{m}$ thick) were dewaxed and blocked in methanol containing $30 \%$ hydrogen peroxide for 20 minutes. Slides were pretreated in citrate buffer $(\mathrm{pH}=6)$ at $80^{\circ} \mathrm{C}$ for 15 minutes, incubated with the primary monoclonal antibody (dilution, 1/100) for 30 minutes, washed, and incubated with the Envision Kit from Dako (Dako, Glostrup, Denmark) for 60 minutes. Thereafter, the immunohistochemical reaction was developed with diaminobenzidine solution containing 30\% hydrogen peroxide (Sigma-Aldrich Chemicals, Vienna, Austria). Finally, the slides were counterstained with haemalaun solution, dehydrated in graded alcohols, and coverslipped with a permanent mounting medium.

\section{Evaluation of tissue slides}

The immunostaining was evaluated with a light microscope (Olympus BX-50) by two of the authors (PO and GS) independently in a blinded fashion. When the two authors disagreed about the score, the slides were reinvestigated by both observers on a multiheaded microscope so that a consensus could be achieved. Normal breast tissue surrounding carcinoma could be evaluated in specimens from 176 patients. The staining intensity was classified as follows: 0, no staining; 1, weak staining; 2, intermediate staining; 3, strong staining. In addition, the percentage of positive tumour cells was calculated. "High" TN expression was arbitrarily defined as a tumour showing at least intermediate staining intensity in more than $50 \%$ of cells. All cases below this cutoff point were considered as "low" expression. When evaluating the connective tissue, only the staining intensity was determined. "High" TN expression was defined as moderate to strong staining, and "low" TN expression as no to weak staining.

\section{Immunoblot analysis}

Western blot analysis of TN and $\alpha$ tubulin was performed as follows: breast cancer tissues, which were morphologically controlled by routine frozen section, were homogenised in RIPA buffer in a blender (Ultraturx; IKA, Vienna, Austria) on ice. Thereafter, the homogenate was centrifuged, the supernatant was collected, and the protein concentration was determined according to the Bradford method (Biorad). Equivalent amounts of supernatant containing $30 \mu \mathrm{g}$ of protein were separated in $12 \%$ sodium dodecyl sulfate polyacrylamide gel on a minigel apparatus (Novex, Groningen, the Netherlands) and transferred on to a nitrocellulose membrane (Schleicher and Schuell, Einbeck, Germany) using a blot chamber (Novex). After blocking with Tris buffered saline (TBS) containing 5\% skimmed milk powder (Fluka, St Louis, Missouri, USA) at room temperature for two hours, the membrane was incubated with the primary antibody at the appropriate dilution: either TN monoclonal antibody (Statens Serum Institute; dilution, $1 / 200$ ) or mouse anti- $\alpha$ tubulin monoclonal antibody (Sigma; dilution, 1/2000). After three wash steps with TBS 1\% Tween-20 (TBS-T), membranes were incubated with the following IgG horseradish peroxidase conjugates: donkey antigoat (dilution, 1/500) and rabbit antimouse (Sigma; dilution, 1/500), for two hours at room temperature, and washed three times in TBS-T. The immunoblots were visualised by enhanced chemiluminescence (Amersham, Little Chalfont, Buckinghamshire, UK).

\section{Statistical methods}

Statistical analysis was performed with SPSS for Windows. The primary end points in our study were disease free survival and overall survival. Thus, survival curves were calculated according to the method of Kaplan and Meier. p Values were evaluated using the log rank test for censored survival data. The follow up time was censored if the patient was lost to follow up. Patients who died without documented disease recurrence $(n=11)$ were considered censored for disease free survival but were excluded for tumour specific overall survival analysis. The relation between TN expression and clinical or tumour parameters was calculated by means of the $\chi^{2}$ test.

\section{RESULTS}

\section{Expression of TN in breast carcinoma specimens}

In tumour adjacent normal breast tissue, high TN expression was mainly found in the connective tissue fibres surrounding normal ducts and lobules (fig lA). In fact, 158 (90\%) of the 176 valuable samples revealed high $\mathrm{TN}$ expression of the connective tissue, whereas only $18(10 \%)$ showed high TN expression in normal breast epithelial cells. In contrast, high TN expression was found in the malignant cells of $131(69 \%)$ tumour samples (fig 1B); however, only seven $(4 \%)$ of the tumour samples revealed high TN expression in the connective tissue surrounding the cancer cells. Of note, TN expression in malignant breast epithelial cells was most pronounced at the invasive front of the tumour lesions. To compare TN protein expression in normal and malignant tissue, we examined protein extracted from breast carcinoma lesions and matched normal breast tissue by western blotting. Overall, the TN protein content and the molecular weight of TN was not different between malignant and normal tissue (fig 2).

\section{Correlation between TN expression in tumour tissue and clinical outcome}

The median follow up time was 10.6 years (range, 3-20). Patients whose tumours had high TN expression had a significantly reduced disease free $(p=0.006$; log rank test; fig 3 ) and tumour specific overall survival ( $p=0 ; 02$; log rank test; fig 4) compared with patients whose tumour cells showed low TN expression. For patients with high TN expression, the median disease free survival was 110 months, but was not reached for patients with low TN expression. Median overall survival of patients with high TN expression was 143 months and was not reached for patients with low TN expression.

By univariate analysis, no correlation was found between TN expression and conventional clinical or tumour parameters, such as age at diagnosis, menopausal status, nodal status, histological grading, or hormone receptor expression (table 1). The only correlation found was between TN expression and histological subtype. Invasive ductal carcinomas showed the highest proportion of high TN expressors. By 

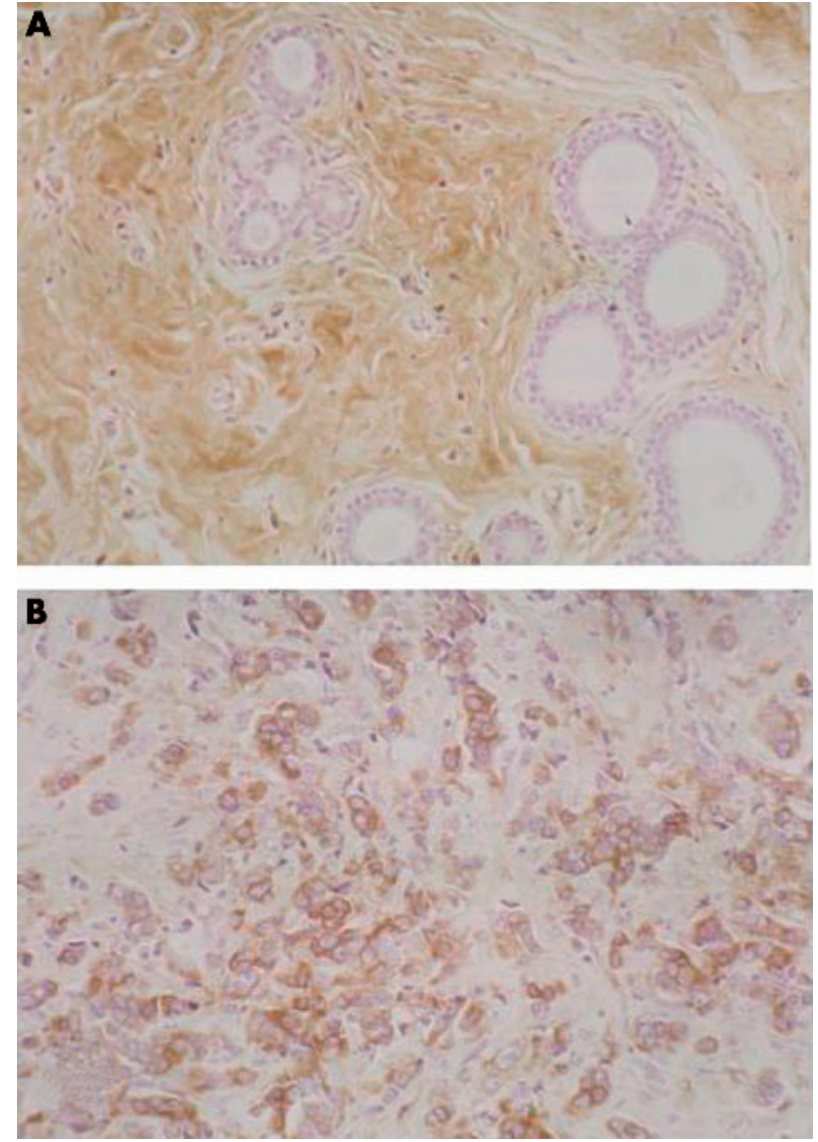

Figure 1 (A) Normal breast tissue with strong staining for tetranectin (TN) in connective tissue fibres. The epithelial component exhibits no TN expression; original magnification, $\times 200$. (B) Immunohistochemical detection of TN expression in breast cancer tissue. The positive reaction is related to the epithelial component, whereas the desmoplastic stroma between the atypical glands lacks TN expression; original magnification, $\times 200$.

multivariate analysis, TN overexpression was found to be an independent prognostic parameter for disease free survival and tumour specific overall survival (table 2).

\section{DISCUSSION}

In our present study, we report for the first time the differential expression of stromal and epithelial TN in normal and malignant breast tissue and a prognostic impact of TN protein expression for human breast carcinoma. In normal breast tissue adjacent to primary breast carcinomas, staining for TN is predominantly localised to the stromal compartment, whereas in malignant tissue TN is mainly expressed by breast carcinoma cells.

$\mathrm{TN}$, a plasminogen kringle 4 binding C-type lectin, was first identified in 1986. ${ }^{29}$ To date, the biological function of TN has

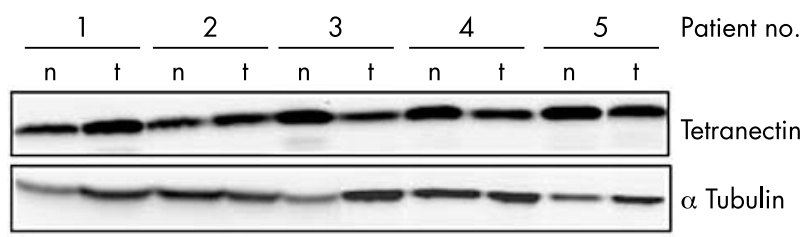

Figure 2 Western blot analysis of tetranectin expression in breast cancer tissue compared with matched normal tissue. This figure depicts the results of five representative cases with breast cancer (1-5); $n$, normal tissue; $t$, tumour tissue.

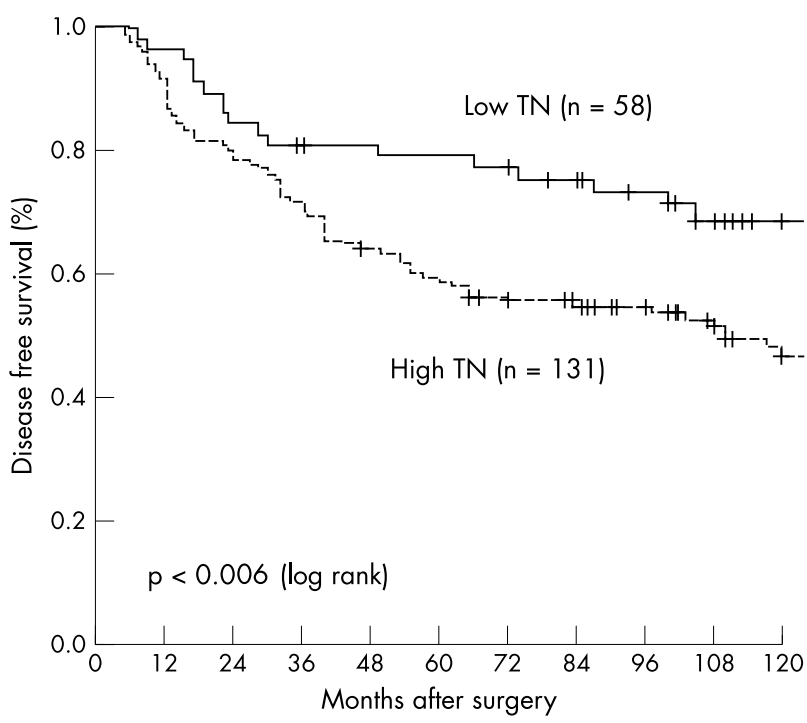

Figure 3 Expression of tetranectin (TN) in tumour cells as a prognostic marker for disease free survival in 189 patients with breast cancer.

not been fully elucidated. Several functions have been assigned to this protein. Deletion of TN gene function in mice resulted in spinal deformity without pathological changes of the musculature. Furthermore, loss of TN led to a softening of the extracellular matrix in bone by aberrant proteolytic processes. ${ }^{30}$ Because proteolytic acitivity is essential for cell motility and migration it is tempting to speculate that in the tumour environment, TN may influence proteolytic processes during tumour cell invasion and metastatic spread. ${ }^{31}{ }^{32}$ Proteolytic enzymes and receptors necessary for cellular invasion can be activated either by invading tumour cells or by adjacent stromal cells. TN released from cancer or stroma cells can activate plasminogen via tissue plasminogen activator release, and trigger proteolysis of collagen, proteoglycans, or other extracellular matrix proteins. In addition, TN can stimulate the activity of proangiogenic factors, either by their proteolytic cleavage into active forms, ${ }^{8}{ }^{2133} 34$ or by activating tissue plasminogen activator. ${ }^{35}$

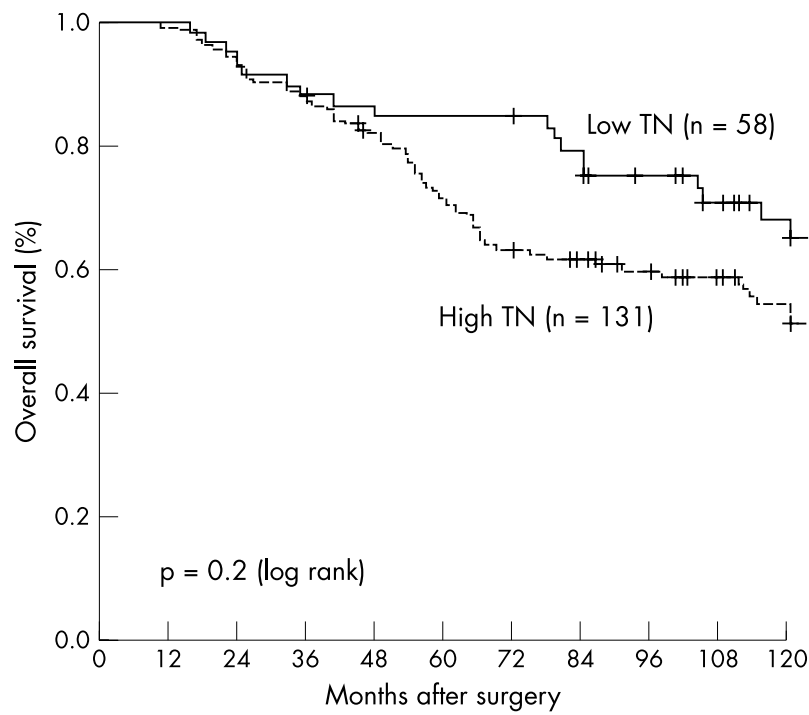

Figure 4 Expression of tetranectin (TN) in tumour cells as a prognostic marker for tumour specific overall survival in 178 patients with breast cancer. Eleven patients without documented disease recurrence at the time of death were excluded from this analysis. 


\begin{tabular}{|c|c|c|c|c|c|c|}
\hline \multirow[b]{3}{*}{ Characteristics } & \multirow[b]{3}{*}{ Patients (N) } & \multicolumn{4}{|c|}{ Tetranectin expression } & \multirow[b]{3}{*}{ p Value } \\
\hline & & \multicolumn{2}{|c|}{ Low } & \multicolumn{2}{|c|}{ High } & \\
\hline & & $\mathrm{N}$ & $\%$ & $\mathbf{N}$ & $\%$ & \\
\hline \multicolumn{7}{|l|}{ Age at diagnosis } \\
\hline$<50$ & 83 & 29 & 35 & 54 & 65 & 0.262 \\
\hline$\geqslant 50$ & 106 & 29 & 27 & 77 & 73 & \\
\hline \multicolumn{7}{|l|}{ Histological type } \\
\hline Ductal & 132 & 34 & 26 & 98 & 74 & 0.039 \\
\hline Lobular & 38 & 14 & 37 & 24 & 63 & \\
\hline Other types & 19 & 10 & 53 & 9 & 47 & \\
\hline \multicolumn{7}{|l|}{ Histological grade } \\
\hline 1 & 10 & 4 & 40 & 6 & 60 & 0.772 \\
\hline$\|$ & 114 & 34 & 30 & 80 & 70 & \\
\hline III & 59 & 17 & 29 & 42 & 71 & \\
\hline NE & 6 & & & & & \\
\hline \multicolumn{7}{|l|}{ Nodal status } \\
\hline pNO & 88 & 29 & 33 & 59 & 67 & 0.528 \\
\hline $\mathrm{pN} 1 / 2 / 3$ & 101 & 29 & 29 & 72 & 71 & \\
\hline \multicolumn{7}{|l|}{ Tumour size } \\
\hline$<2 \mathrm{~cm}$ & 71 & 21 & 30 & 50 & 70 & 0.585 \\
\hline $2-5 \mathrm{~cm}$ & 92 & 27 & 29 & 65 & 71 & \\
\hline$>5 \mathrm{~cm}$ & 8 & 1 & 12 & 7 & 88 & \\
\hline Unknown & 18 & & & & & \\
\hline \multicolumn{7}{|c|}{ Oestrogen receptor (ER) } \\
\hline ER neg: 0-9 fmol & 37 & 13 & 35 & 24 & 65 & 0.322 \\
\hline ER pos: $>9$ fmol & 127 & 34 & 27 & 93 & 73 & \\
\hline Unknown & 25 & & & & & \\
\hline \multicolumn{7}{|c|}{ Progesterone receptor (PR) } \\
\hline PR neg: 0-9 fmol & 54 & 12 & 22 & 42 & 78 & 0.202 \\
\hline PR pos: $>9$ fmol & 110 & 35 & 32 & 75 & 68 & \\
\hline Unknown & 25 & & & & & \\
\hline
\end{tabular}

Serum concentrations of soluble TN were found to be decreased in patients with breast, colon, endometrial, and ovarian carcinoma. ${ }^{24} 25$ 36-38 Higher TN concentrations in serum indicated a more favourable prognosis. Moreover, soluble TN values were found to be a significant predictor of chemoresponsiveness in patients with metastatic breast cancer. ${ }^{39}$

Our results in breast cancer suggest that during carcinogenesis and tumour progression, TN production is shifted from the stromal to the epithelial compartment. However, the total amount of TN in breast carcinomas, as demonstrated by western blot analysis, does not differ from adjacent normal breast tissue. These findings are concordant with those

Table 2 Multivariate analysis of various prognostic markers including tetranectin (TN) expression

\begin{tabular}{|c|c|c|c|c|c|c|}
\hline & \multicolumn{3}{|l|}{ DFS } & \multicolumn{3}{|l|}{ DSOS } \\
\hline & $p$ Value & RR & $95 \% \mathrm{Cl}$ & p Value & RR & $95 \% \mathrm{Cl}$ \\
\hline Nodal status & 0.005 & 2.1 & 1.2 to 3.4 & 0.002 & 2.6 & $1.4-4.7$ \\
\hline TN overexpression & 0.03 & 2.0 & 1.1 to 3.9 & 0.02 & 2.3 & $1.1-4.6$ \\
\hline \multicolumn{7}{|l|}{ Tumour size } \\
\hline$<2 \mathrm{~cm} \vee 2-5 \mathrm{~cm}$ & NS & & & NS & & \\
\hline$<2 \mathrm{~cm} \mathrm{v}>5 \mathrm{~cm}$ & 0.02 & 3.1 & 1.2 to 7.8 & 0.02 & 3.0 & $1.2-7.7$ \\
\hline $\begin{array}{l}\text { Histological grade } \\
\mid+\|v\| \|\end{array}$ & 0.02 & 1.8 & 1.0 to 3.9 & 0.001 & 2.6 & $1.5-4.5$ \\
\hline $\begin{array}{l}\text { Progesterone } \\
\text { receptor }\end{array}$ & \multicolumn{3}{|l|}{ NS } & \multirow{2}{*}{\multicolumn{3}{|c|}{ NS }} \\
\hline Oestrogen receptor & \multicolumn{3}{|l|}{ NS } & & & \\
\hline \multicolumn{7}{|c|}{$\begin{array}{l}\mathrm{Cl} \text {, confidence interval; NS, not significant; RR, relative risk. } \\
\text { Patients who died without documented disease recurrence }(n=11) \text { were } \\
\text { considered censored for disease free survival, but were excluded for } \\
\text { disease specific overall survival analysis. } \\
\text { DFS, disease free survival; DSOS, disease specific overall survival. }\end{array}$} \\
\hline
\end{tabular}

reported for the expression of tissue plasminogen activator in breast carcinoma. ${ }^{40}$

"Our results in breast cancer suggest that during carcinogenesis and tumour progression, tetranectin production is shifted from the stromal to the epithelial compartment" $^{\prime \prime}$

Previous studies of TN expression in normal breast tissue revealed a faintly perceptible staining of epithelium and a moderate immunoreactivity of stromal components. ${ }^{41}$ Our findings in tumour specimens containing malignant and adjacent normal tissue are in keeping with these observations. Costantini et al reported strong expression of

\section{Take home messages}

- In normal breast tissue adjacent to primary breast carcinomas, staining for tetranectin (TN) was predominantly localised to the stromal compartment, whereas in malignant tissue TN was mainly expressed by breast carcinoma cells

- Strong TN immunoreactivity in tumour tissue was predictive of poor disease free and tumour specific overall survival

- TN may play a role in invasiveness and the metastatic spread of human breast cancer

- Larger studies will be needed before the TN marker can be used as an additional tool to improve the prognostic evaluation of human breast cancer 
plasminogen activators in the epithelial component of tumour samples, whereas the desmoplastic stroma exhibited a positive reaction for fibrinogen and its D fragment, plasmin. ${ }^{42}$

The clinical relevance of TN expression in breast cancer is most evident from its prognostic impact. High TN expression in breast cancer was shown to be an indicator of poor disease free and tumour specific survival independent from tumour stage, histological grading, nodal and hormone receptor status.

In summary, our findings suggest an important role for TN in breast cancer biology. Confirmatory studies in larger patient populations will be necessary before the TN marker can be used as an additional tool to improve the prognostic evaluation of human breast cancer.

\section{ACKNOWLEDGMENTS}

We thank I Tschörner (Department of Pathology, University of Innsbruck) for her excellent technical assistance.

\section{Authors' affiliations \\ P Obrist, C Ensinger, D Fong, T Brunhuber, G Schäfer, M Varga,} Department of Pathology, University of Innsbruck, Muellerstr. 44, A6020 Innsbruck, Austria

G Spizzo, G Gastl, Division of Haematology and Oncology, University of Innsbruck

R Margreiter, A Amberger, Tyrolean Cancer Research Institute, University of Innsbruck

M Christiansen, Department of Clinical Biochemistry, Statens Serum Institut, DK-2300 Copenhagen, Denmark

\section{REFERENCES}

1 Durkin ME, Naylor SL, Albrechtsen R, et al. Assignment of the gene for human tetranectin (TNA) to chromosome $3 \mathrm{p} 22 \rightarrow \mathrm{p} 21.3$ by somatic cell hybrid mapping. Cytogenet Cell Genet 1997;76:39-40

2 Nielsen BB, Kastrup JS, Rasmussen H, et al. Crystallization and molecularreplacement solution of a truncated form of human recombinant tetranectin. Acta Crystallogr D Biol Crystallogr 2000;56:637-9

3 Fuhlendorff J, Clemmensen I, Magnusson S. Primary structure of tetranectin, a plasminogen kringle 4 binding plasma protein: homology with asialoglycoprotein receptors and cartilage proteoglycan core protein Biochemistry 1987;26:6757-64.

4 Jaquinod M, Holtet TL, Etzerodt M, et al. Mass spectrometric characterisation of post-translational modification and genetic variation in human tetranectin. Biol Chem 1999;380:1307-14.

5 Clemmensen I. Interaction of tetranectin with sulphated polysaccharides and trypan blue. Scand J Clin Lab Invest 1989;49:719-25.

6 Lorentsen RH, Graversen JH, Caterer NR, et al. The heparin-binding site in tetranectin is located in the $\mathrm{N}$-terminal region and binding does not involve the carbohydrate recognition domain. Biochem J 2000;347:83-7.

7 Kluft C, Jie AF, Los P, et al. Functional analogy between lipoprotein(a) and plasminogen in the binding to the kringle 4 binding protein, tetranectin. Biochem Biophys Res Commun 1989;161:427-33.

8 Kluft C, Los P, Clemmensen I, et al. Quantitation of plasma levels of tetranectin-effects of oral contraceptives, pregnancy, treatment with Lasparaginase and liver cirrhosis. Thromb Haemost 1989;62:792-6.

9 Nielsen H, Clemmensen I, Kharazmi A. Tetranectin: a novel secretory protein from human monocytes. Scand J Immunol 1993;37:39-42.

10 Borregaard N, Christensen L, Bejerrum OW, et al. Identification of a highly mobilizable subset of human neutrophil intracellular vesicles that contains tetranectin and latent alkaline phosphatase. J Clin Invest 1990;85:408-16.

11 Clemmensen I, Lund LR, Christensen L, et al. A tetranectin-related protein is produced and deposited in extracellular matrix by human embryonal fibroblasts. Eur J Biochem 1991;195:735-41.

12 Wewer UM, Iba K, Durkin ME, et al. Tetranectin is a novel marker for myogenesis during embryonic development, muscle regeneration, and muscle cell differentiation in vitro. Dev Biol 1998;200:247-59

13 Wewer UM, Ibaraki K, Schjorring $P$, et al. A potential role for tetranectin in mineralization during osteogenesis. J Cell Biol 1994;127:1767-75.
14 Kamper EF, Kopeikina L, Mantas A, et al. Tetranectin levels in patients with acute myocardial infarction and their alterations during thrombolytic treatment. Ann Clin Biochem 1998;35:400-7.

15 Christensen L, Johansen $\mathrm{N}$, Jensen BA, et al. Immunohistochemical localization of a novel, human plasma protein, tetranectin, in human endocrine tissues. Histochemistry 1987;87:195-9.

16 Christensen L, Clemmensen I. Differences in tetranectin immunoreactivity between benign and malignant breast tissue. Histochemistry 1991:95:427-33.

17 Arvanitis DL, Kamper EF, Kopeikina L, et al. Tetranectin expression in gastric adenocarcinomas. Histol Histopathol 2002;17:471-5.

18 De Vries TJ, De Wit PE, Clemmensen I, et al. Tetranectin and plasmin/ plasminogen are similarly distributed at the invasive front of cutaneous melanoma lesions. J Pathol 1996;179:260-5.

19 Blaakaer J, Hogdall CK, Micic S, et al. Ovarian carcinoma serum markers and ovarian steroid activity - is there a link in ovarian cancer? A correlation of inhibin, tetranectin and CA-125 to ovarian activity and the gonadotropin levels. Eur J Obstet Gynecol Reprod Biol 1995;59:53-6.

20 Hogdall CK, Hogdall EV, Hording U, et al. Plasma tetranectin and ovarian neoplasms. Gynecol Oncol 1991;43:103-7.

21 Skriver L, Nielsen LS, Kristensen P, et al. [Biochemical mechanism for extracellular proteolysis. Tissue destruction and cancer.] Nord Med 1983:98:238-41.

22 Jensen BA, Clemmensen I. Plasma tetranectin is reduced in cancer and related to metastasia. Cancer 1988;62:869-72.

23 Hogdall CK, Mogensen O, Tabor A, et al. The role of serum tetranectin, CA 125 , and a combined index as tumor markers in women with pelvic tumors. Gynecol Oncol 1995;56:22-8.

24 Hogdall CK, Hording U, Norgaard-Pedersen B, et al. Serum tetranectin and CA-125 used to monitor the course of treatment in ovarian cancer patients. Eur J Obstet Gynecol Reprod Biol 1994;57:175-8.

25 Hogdall CK, Christensen L, Clemmensen I. [Tetranectin, a plasma and tissue protein-a prognostic marker of breast and ovarian cancer.] Ugeskr Laeger 1994;156:6190-5

26 Hogdall CK, Hogdall EV, Hording U, et al. Pre-operative plasma tetranectin as a prognostic marker in ovarian cancer patients. Scand J Clin Lab Invest 1993;53:741-6.

27 Hogdall CK, Christensen L, Clemmensen I. The prognostic value of tetranectin immunoreactivity and plasma tetranectin in patients with ovarian cancer. Cancer 1993:72:2415-22.

28 Hogdall CK, Christiansen M, Christensen L, et al. Monoclonal antibodies against human tetranectin, epitope characterization and use in immunohistochemistry. Clin Chim Acta 1997;258:159-77.

29 Clemmensen I, Petersen LC, Kluft C. Purification and characterization of a novel, oligomeric, plasminogen kringle 4 binding protein from human plasma: tetranectin. Eur J Biochem 1986;156:327-33.

30 Iba K, Durkin ME, Johnsen L, et al. Mice with a targeted deletion of the tetranectin gene exhibit a spinal deformity. Mol Cell Biol 2001;21:7817-25.

31 Schmitt $M$, Janicke F, Graeff H. Tumour-associated fibrinolysis: the prognostic relevance of plasminogen activators UPA and IPA in human breast cancer. Blood Coagul Fibrinolysis 1990; 1:695-702.

32 Bell WR. The fibrinolytic system in neoplasia. Semin Thromb Hemost 1996;22:459-78.

33 Dano K, Andreasen PA, Grondahl-Hansen J, et al. Plasminogen activators, tissue degradation, and cancer. Adv Cancer Res 1985;44:139-266.

34 Dvorak HF, Dickersin GR, Dvorak AM, et al. Human breast carcinoma: fibrin deposits and desmoplasia. Inflammatory cell type and distribution. Microvasculature and infarction. J Natl Cancer Inst 1981;67:335-45.

35 Flaumenhaft $R$, Abe M, Mignatti $P$, et al. Basic fibroblast growth factorinduced activation of latent transforming growth factor beta in endothelial cells: regulation of plasminogen activator activity. J Cell Biol 1992; 1 18:901-9.

36 Lundstrom MS, Hogdall CK, Nielsen AL, et al. Serum tetranectin and CA125 in endometrial adenocarcinoma. Anticancer Res 2000;20:3903-6.

37 Deng X, Hogdall EV, Hogdall CK, et al. The prognostic value of pretherapeutic tetranectin and CA-125 in patients with relapse of ovarian cancer. Gynecol Oncol 2000;79:416-19.

38 Hogdall CK, Christiansen M, Norgaard-Pedersen B, et al. Plasma tetranectin and colorectal cancer. Eur J Cancer 1995;31A:888-94.

39 Hogdall CK, Soletormos G, Nielsen D, et al. Prognostic value of serum tetranectin in patients with metastatic breast cancer. Acta Oncol 1993:32:631-6.

40 Sumiyoshi K, Serizawa K, Urano T, et al. Plasminogen activator system in human breast cancer. Int J Cancer 1992;50:345-8.

41 Christensen L, Clemmensen I. Tetranectin immunoreactivity in normal human tissues. An immunohistochemical study of exocrine epithelia and mesenchyme. Histochemistry 1989;92:29-35.

42 Costantini V, Zacharski LR, Memoli VA, et al. Occurrence of components of fibrinolysis pathways in situ in neoplastic and nonneoplastic human breast tissue. Cancer Res 1991:51:354-8. 